\title{
Ascitis grave en varón joven: hay causas malignas rápidamente mortales
}

\author{
María Luisa García-de-Aguinaga' ${ }^{1}$, María José Gómez-Crespo², Juan Antonio Gómez-Patiño³, Frida Vallejo-Somohano , Noemí García- \\ Miralles 5 \\ 'Servicio de Medicina Interna. Hospital El Escorial. Universidad Francisco de Vitoria, Madrid, España \\ 25ervicio de Hematología. Hospital El Escorial. Universidad Francisco de Vitoria, Madrid, España \\ ${ }^{3}$ Servicio de Radiología. Hospital El Escorial. Universidad Francisco de Vitoria, Madrid, España \\ ${ }^{4}$ Servicio de Medicina Familiar y Comunitaria. Hospital El Escorial, Madrid, España \\ ${ }_{5}^{5}$ Servicio de Anatomía Patológica. Hospital El Escorial. Universidad Francisco de Vitoria, Madrid, España
}

Recibido: 04/01/2021

Aceptado: 30/01/2021

En línea: 30/04/2021

Citar como: García-de-Aguinaga ML, Gómez-Crespo MJ, Gómez-Patiño JA, Vallejo-Somohano F, García-Miralles N. Ascitis grave en varón joven: hay causas malignas rápidamente mortales. Rev Esp Casos Clin Med Intern (RECCMI). 2021 (abril); 6(1): 27-31. doi: 10.32818/reccmi.a6n1a9.

Cite this as: García-de-Aguinaga ML, Gómez-Crespo MJ, Gómez-Patiño JA, Vallejo-Somohano F, García-Miralles N. Severe ascites in young men: there are rapidly fatal malignant causes. Rev Esp Casos Clin Med Intern (RECCMI). 2021 (April); 6(1): 27-31. doi: 10.32818/reccmi.a6n1a9.

Autor para correspondencia: María Luisa García-de-Aguinaga. marisa_aguinaga@hotmail.com

\begin{aligned} Palabras clave \\ \hline$\triangleright$ Burkitt Linfoma \\ $\triangleright$ Linfoma No Hodgkin \\ $\triangleright$ Infecciones virus \\ $\quad$ Epstein-Barr \end{aligned}

Keywords

$\triangleright$ Burkitt Lymphoma

$\triangleright$ Lymphoma Non-Hodgkin

$\triangleright$ Epstein-Barr Virus Infections

\begin{abstract}
Resumen
Varón de 37 años que acude a Urgencias por distensión abdominal. Se constata la evidencia de ascitis con masa periduodenal, infiltración peritoneal y trombosis venosa mesentérica. Es diagnosticado en 48 horas de un linfoma de Burkitt esporádico abdominal con afectación cerebral y tratado con quimioterapia, protocolo Burkimab-13. Presenta remisión completa a los 3 meses, que permanece a los dos años del diagnóstico. Es vital sospechar con rapidez esta entidad puesto que el tamaño del tumor se duplica diariamente; sin tratamiento es mortal mientras que, con quimioterapia, la supervivencia alcanza el 65-95\%.

Abstract
A 37-year-old male attended the emergency room with abdominal distension. He was found to have ascites
with a periduodenal mass, peritoneal infiltration and mesenteric venous thrombosis. He also presented with
sudden binocular diplopia. He was diagnosed within $48 \mathrm{~h}$ with sporadic abdominal Burkitt's lymphoma with
brain involvement and treated with chemotherapy, Burkimab-13 protocol. He achieved complete remission af-
ter three months and has remained in remission two years after diagnosis. It is critical to suspect this lymphoma
quickly since the tumor doubles daily in size and is fatal if left untreated, whereas survival reaches $65-95 \%$ with
chemotherapy.
\end{abstract}

\section{Puntos destacados}

$\triangleright$ Ante ascitis en jóvenes, hay que descartar etiologías malignas

$\triangleright$ Es importante realizar ecografía y paracentesis rápidas, incluso en Urgencias.

$\triangleright$ El linfoma de Burkitt es poco frecuente, pero mortal sin tratamiento. En Occidente, es más probable la variante esporádica en varones jóvenes.

\section{Introducción}

El linfoma de Burkitt (LB) es el linfoma más agresivo, duplicando diariamente su tamaño. La forma más frecuente es la endémica, en niños africanos con masas tumorales mandibulares, mientras que la esporádica abdominal ocurre en varones jóvenes de occidente, como el caso que nos ocupa. La patogenia se basa en la translocación $(8 ; 14)$ del oncogen Myc y se desconoce el papel del virus de Epstein Barr (VEB) que está presente en el 90\% de las formas endémicas?

El LB es infrecuente y requiere el diagnóstico rápido para iniciar cuanto antes un tratamiento curativo.

\section{Caso clínico}

Antecedentes personales y enfermedad actual

Varón de 37 años sin hábitos tóxicos ni antecedentes de interés, que acude a Urgencias por distensión abdominal progresiva en los últimos 5 días hasta impedirle la ingesta. En el último mes, refería molestias difusas en abdomen, digestiones más pesadas, dorsalgia, disminución de la diuresis, leve pérdida de peso no cuantificada y sudoración profusa. 
García-de-Aguinaga ML, Gómez-Crespo MJ, Gómez-Patiño JA, Vallejo-Somohano F, García-Miralles N. Ascitis grave en varón joven: hay causas malignas rápidamente mortales

\section{Exploración física}

Obeso, afebril, abdomen globuloso, distendido, matidez cambiante en flancos. El resto es normal.

\section{Pruebas complementarias y evolución}

Al confirmar ascitis por ecografía, ingresa y se realiza analítica completa, TAC abdomen, paracentesis diagnóstica y, a la vista de estos, biopsia peritoneal y masa abdominal.

En nuestro hospital de segundo nivel, se realiza:

- Hemograma, coagulación y orina normales. serología VIH negativa.

- Bioquímica inicial: creatinina 0,93 mg/dL (0,6-1,25); filtrado glomerular 91 mL/min (> 60); ácido úrico 14,4mg/dL (3,5-7,2), GOT 65 (< 40) y GPT 55 $\mathrm{UI} / \mathrm{I}$ ( $\leq 55), \mathrm{LDH} 1.360 \mathrm{UI} / \mathrm{L}$ (110-245), albúmina 3,8 g/dL (3,5-5,2), ferritina $1.128 \mathrm{ng} / \mathrm{mL}$ (20-270), PCR 4,34 mg/dL (v60). Resto normal.

- Ecografía abdominal (Figura 1): líquido libre y engrosamiento omental.

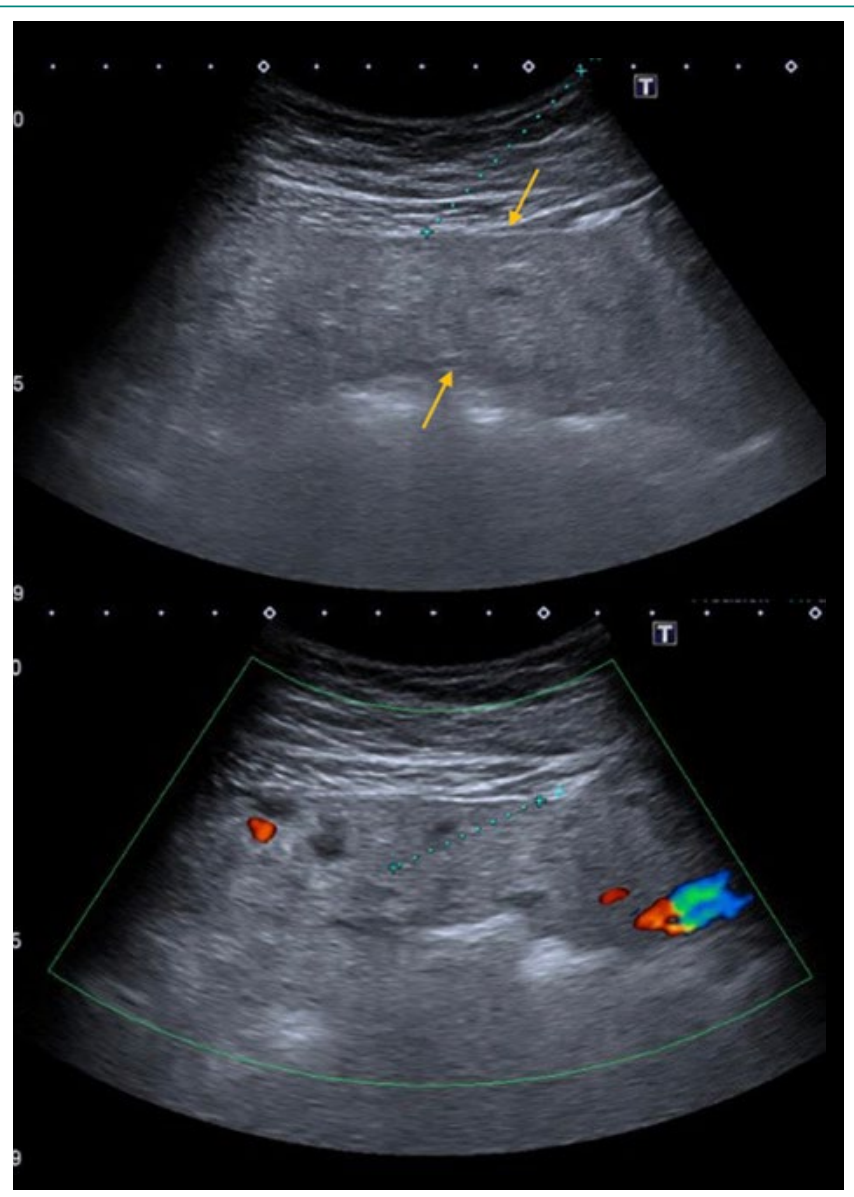

Figura 1. Ecografía. Engrosamiento del omento mayor, aspecto ecográfico (flechas naranjas). Planificación con ecografía-Doppler del trayecto de biopsia realizada en región periumbilical con sistema coaxial y aguja Tru-cut 18G (líneas de puntos azules).

- TAC Abdomen (Figura 2): masa intraabdominal de $8 \mathrm{~cm}$ en cuarta porción del duodeno/ángulo de Treitz e inicio de yeyuno. Importantes adenopatías intra y retroperitoneales, imágenes nodulares por probables implantes en hipocondrio izquierdo, afectación del epiplón y del mesenterio tipo omental cake, compatible con linfoma como primera posibilidad y trombosis en segmento distal de vena mesentérica'

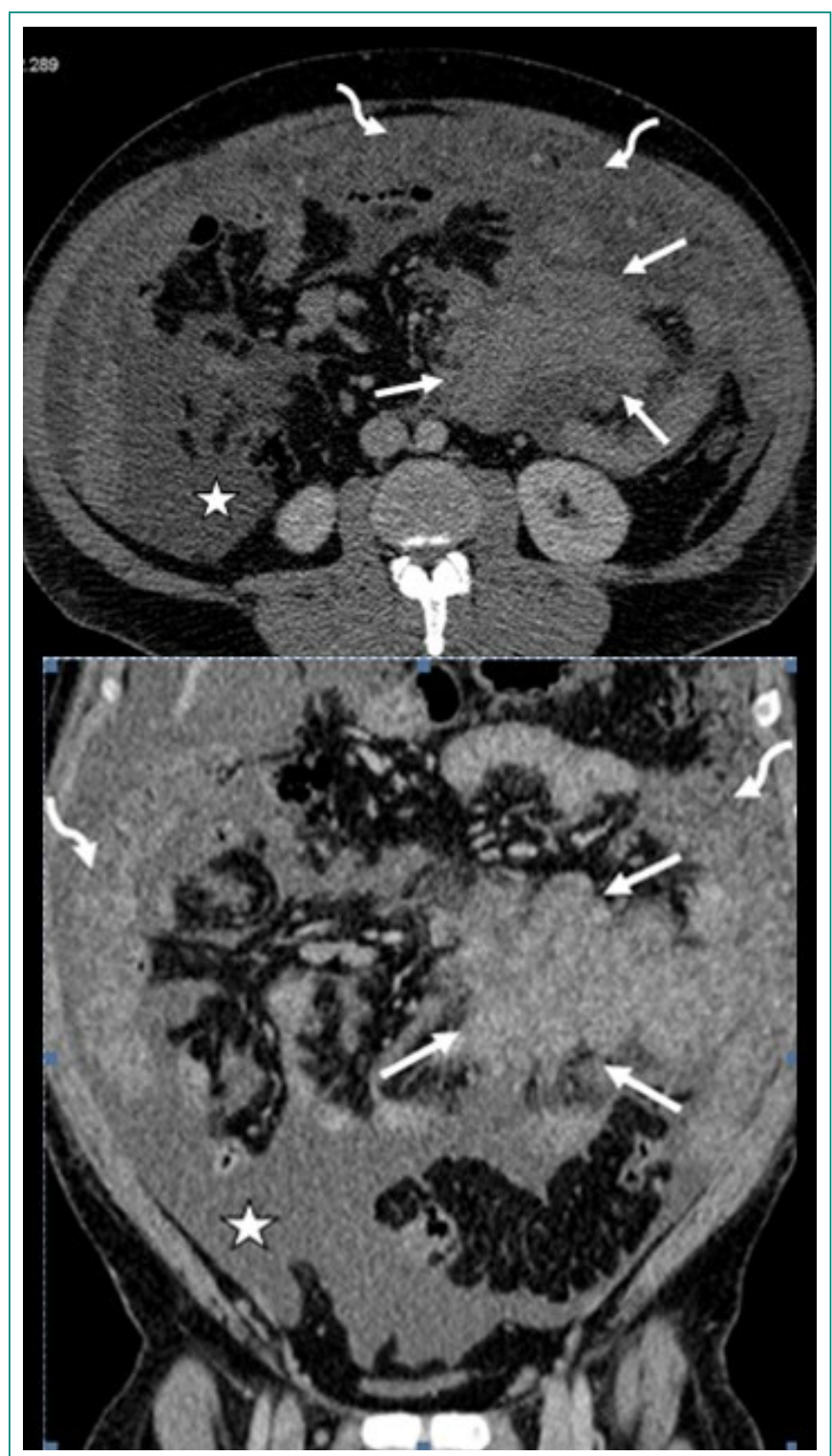

Figura 2. TAC abdomen, corte trasversal y coronal. Masa mesentéricaconglomerado adenopático, en unión de $4^{a}$ porción duodeno, ángulo de Treitz e inicio del yeyuno (flechas rectas blancas), engrosamiento peritonealomental cake (flechas onduladas) y ascitis (estrella).

- Liquido ascítico: aspecto amarillo turbio. Leucocitos 40.000/microlitro con polimorfonucleares $80 \%$ y mononucleares $14 \%$. Se observa un alto porcentaje de células de origen no filiado. Bioquímica al tiempo: glucosa $<5 \mathrm{mg} / \mathrm{dL}$, ph 7,13, LDH > 4.500 UI/L, proteínas 4,1 g/dL, GOT 621. Cumple criterios de exudado con proteínas $>2,5 \mathrm{~g} / \mathrm{dl}$. Gram no se observa y ADA (adenosina de-aminasa) negativo.

- Citología de liquido ascítico y biopsia peritoneal con aguja gruesa (Figura 3): linfoma no Hodgkin de alto grado, compatible con LB.

\section{Evolución}

El segundo día del ingreso, desarrolla fallo renal y diplopia binocular brusca por paresia del VI par craneal derecho, confirmando posteriormente infiltración tumoral en liquido cefalorraquídeo (LCR). Se le trata con enoxaparina por trombosis de vena mesentérica vista en TAC, sueroterapia y rasburicasa para el síndrome de lisis tumoral, así como con cobertura antibiótica con piperacilina/ tazobactam intravenoso. 


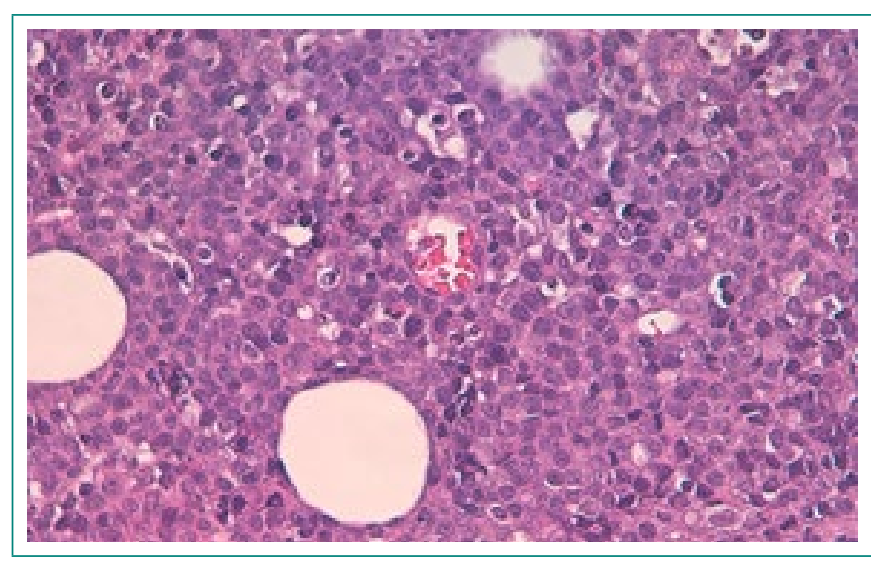

Figura 3. Biopsia de masa abdominal. Imagen en cielo estrellado.
La biopsia es compatible con LB y se traslada urgente a hematología de hospital de tercer nivel para tratamiento oncológico preferente.

En el hospital de tercer nivel, se realiza:

- PET (tomografía con emisión de positrones)-TAC, con hallazgos de malignidad: engrosamiento difuso peritoneal y mesentérico, nódulo pulmonar, múltiples lesiones óseas. Captaciones lineales musculares inespecíficas.

- RNM cerebral: lesiones focales intraóseas sospechosas de malignidad en la calota craneal y cuerpos vertebrales C2 y C3. En el clivus, lesión con extensión intraselar y en el seno cavernoso derecho.

- LCR: infiltración neoplásica.

- Ecocardiograma: normal.

- Biopsia de médula ósea: patrón en cielo estrellado, inmunohistoquímica definitoria de LB, Ki-67 99\% y translocación (8;14).

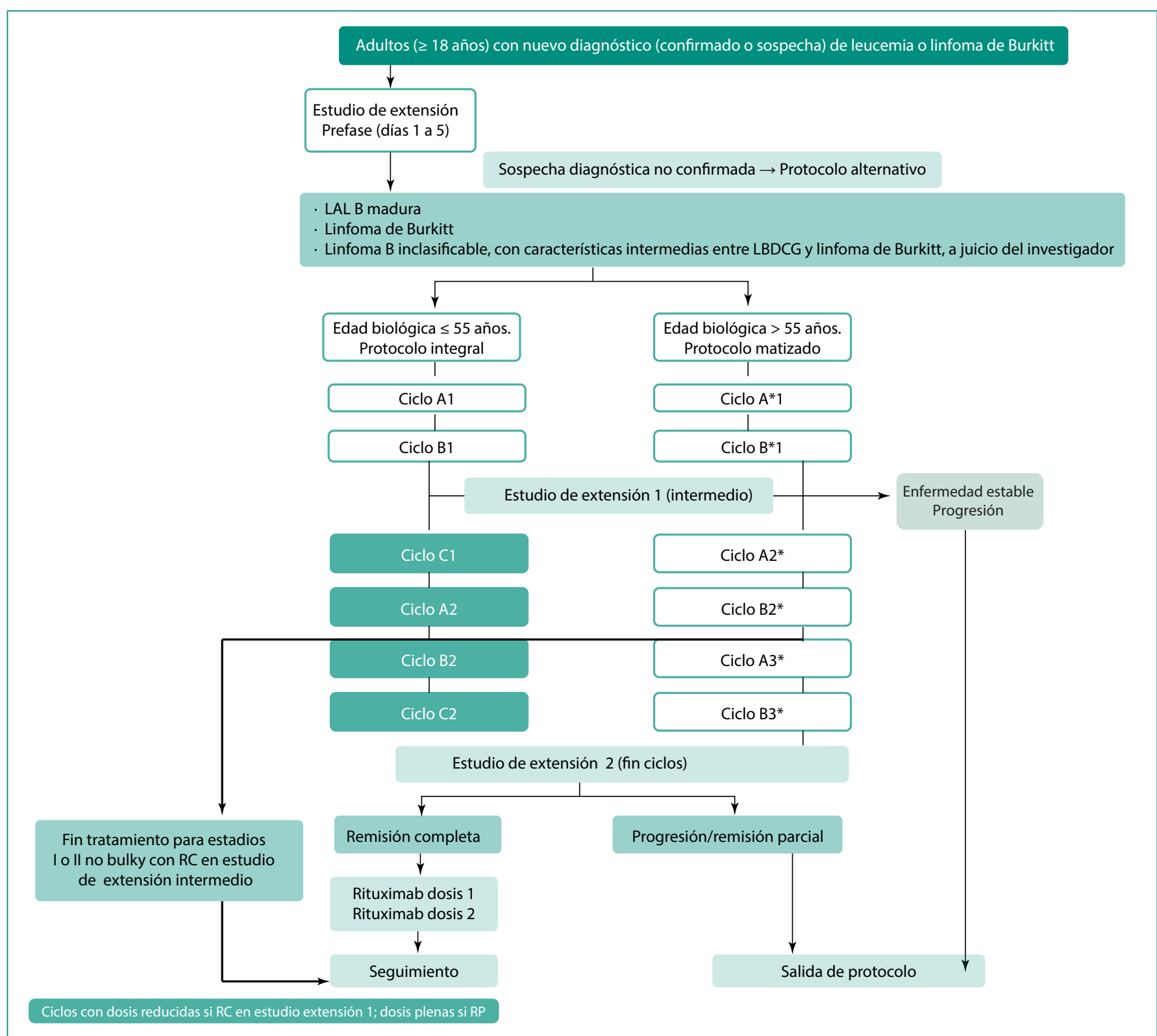

Figura 4. . Tratamiento del linfoma de Burkitt, Protocolo Burkimab-13 (fuente: PETHEMA Programa Español de Terapéutica en Hematología de la Sociedad Española de Hematología y GEL-TAMO Grupo Español de Linfomas-Trasplante de Médula ósea. https://www.sehh.es/servicios-para-los-socios/premios/560servicios-para-los-socios/pethema/protocolos/burkimab). Agentes quimioterápicos: - En prefase: Ciclofosfamida, Prednisona y Metotrexato intratecal - En ciclo A1: Rituximab, Metotrexato, Dexametasona, Ifosfamida, Vincristina, Etopósido (VP16), Citarabina - En ciclo B1: Rituximab, Metotrexato, Dexametasona, Ciclofosfamida, Vincristina, Doxorrubicina. 
Se trató según el protocolo Burkimab-13 (Figura 4) para menores de 55 años, con remisión parcial tras 2 ciclos por persistencia de lesión en clivus (que desapareció en RNM cerebral a los 3 meses). Como complicaciones, tuvo fracaso renal agudo por síndrome de lisis tumoral, episodios de neutropenia febril requiriendo tratamiento con factor estimulante de colonias (G-CSF) y diarrea por mucositis, resueltos.

En el seguimiento a los 18 meses, se repitieron el PET, TAC, LCRY BMO, sin evidencia de infiltración neoplásica, considerándolo en remisión completa (RC).

\section{Diagnóstico}

Linfoma de Burkitt esporádico, estadio IV B, con masa abdominal-ascitis, infiltración de SNC y trombosis venosa mesentérica.

\section{Discusión y conclusión}

El linfoma de Burkitt es el linfoma más agresivo que se conoce, duplicándose cada 24 horas y el 70\% se presenta en estadio diseminado III o IV al diagnóstico. Es un linfoma no Hodgkin de células B maduras'.

Presenta tres formas clínicas: 1) la endémica o africana es 30-50 veces más frecuente y afecta a niños africanos menores de 7 años con tumoraciones en la cara; 2) la esporádica en occidente, que produce masa intraabdominal y 3) la asociada a inmunodeficiencias y VIH, con adenopatías múltiples (Tabla 1).

El LB supone el 30\% de los linfomas en pediatría, pero menos del $1 \%$ de los linfomas no Hodgkin en adultos.

En la etiopatogenia está implicado el VEB y es esencial la translocación del protooncogen MYC con el gen de las inmunoglobulinas, bien de cadenas pesadas $\mathrm{t}(8 ; 14)$, que ocurre en el $80 \%$ de los casos, o de cadenas ligeras $t(2 ; 8)$ o $t(8 ; 22)^{3}$. Este oncogen MYC produce la transformación y proliferación de células B tu morales y la apoptosis celular masiva, con aparición de detritus e hipercatabolismo que explica el aumento de LDH y ácido úrico.

El diagnóstico se realiza con citologías o biopsias de los órganos afectados (masa abdominal en LB esporádico, hueso en LB endémico).

Los tipos histológicos son el plasmocitoide (en VIH), atípico o pleomórfico, y el clásico ${ }^{4}$. Este último tiene población uniforme de linfocitos B de talla intermedia, con citoplasma basófilo, núcleo grande, grumos cromatínicos, vacuolas lipídicas, numerosas mitosis, intensa apoptosis con detritus fagocitados por macrófagos («cuerpos tingibles») dando el aspecto de imagen «en cielo estrellado». Presenta una alta proliferación con fracción células Ki-67 positivas próxima al 100\%. Las células son positivas para marcadores CD45, CD20, CD79, CD10, BCL6, C-Myc, siendo negativas para CD3, CD5/BCL2/ CD23/CiclinaD1/Tdt.

El diagnóstico diferencial hay que realizarlo con neoplasias no hematolinfoides (en hueso: el sarcoma de Ewing, y en abdomen: tumor de Wilms y neuroblastomas en niños, tumores del estroma gastrointestinal en adultos) y otras hematolinfoides, como leucemia/linfoma linfoblástico de precursores B O T, leucemia mieloide indiferenciada, linfoma B del manto y linfoma B difuso de células grandes.

El tratamiento debe controlar el síndrome de lisis tumoral e iniciar en las primeras 48 horas quimioterapia intensiva con ciclofosfamida, vincristina, metotrexate, doxorrubicina y citarabina ${ }^{5,6}$. Siempre con quimioterapia intratecal y esteroides ${ }^{7}$ porque el $40 \%$ puede tener recidiva cerebral en el primer año. Tras los 2 primeros ciclos, se evalúa respuesta clínica, analítica y PET-TAC, determinando remisión completa $(\mathrm{RC})$, parcial o refractariedad.

El seguimiento será cada 3-4 meses el primer año; cada 6 meses, el segundo año y, después, anual.

En cuanto al pronóstico, con tratamiento, las tasas de RC son del 65-95\%. Es peor según la edad y el estadio inicial del LB ${ }^{8}$. Las recaídas son poco frecuentes y ocurren generalmente antes de un año. El tratamiento de rescate con quimioterapia es poco eficaz y el trasplante de progenitores hematopoyéticos es una opción.

\section{Bibliografía}

1. Molyneux EM, Rochford R, Griffin B, Newton R, Jackson G, Menon G, et al. Burkitt's lymphoma. Lancet. 2012; 379(9822): 1234-44. doi: 10.1016/S01406736(11)61177.

2. Manning MA, Somwaru AS, Mehrotra AK, Levine MS. Gastrointestinal Lymphoma: Radiologic-Pathologic Correlation. Radiol Clin North Am. 2016; 54(4): 765-84. doi:10.1016/j.rcl.2016.03.007.

3. Magrath I. Epidemiology: clues to the pathogenesis of Burkitt lymphoma. Br J Haematol. 2012; 156(6): 744-56. doi: 10.1111/j.13652141.2011.09013.x.

\begin{tabular}{|c|c|c|c|}
\hline Formas clínicas & $\begin{array}{l}\text { Endémica } \\
\text { (la más frecuente) }\end{array}$ & Esporádica & Asociada a inmunodeficiencia \\
\hline Distribución geográfica & $\begin{array}{l}\text { África Ecuatorial y Papúa Nueva Guinea, } \\
\text { en zonas de malaria }\end{array}$ & $\begin{array}{l}\text { Población caucásica de Estados Unidos, } \\
\text { Centroamérica y Europa }\end{array}$ & Amplia distribución geográfica \\
\hline Incidencia anual & 3-6 casos/100.000 niños & 2 casos/1.000.000 personas & - \\
\hline Población afectada & $\begin{array}{l}\text { Niños de } 4 \text { a } 7 \text { años } \\
\text { Varones/mujeres 2/1 }\end{array}$ & $\begin{array}{l}\text { Más frecuente en menores de } 35 \text { años } \\
\text { Varones/mujeres 3-4/1 }\end{array}$ & $\begin{array}{l}\text { Personas con VIH-SIDA (CD4 > 200) } \\
\text { y trasplantes de órganos }\end{array}$ \\
\hline Clínica & $\begin{array}{l}\text { Tumoración de huesos faciales en 70\% } \\
\text { casos (mandíbula y periorbitarios). } \\
\text { Además afectación del SNC y abdomen }\end{array}$ & $\begin{array}{l}\text { Masa intraabdominal (ileocecal) en 90\% } \\
\text { casos. } \\
\text { Además invasión de médula ósea, } \\
\text { ganglios, SNC y pleural }\end{array}$ & $\begin{array}{l}\text { Adenopatías difusas (es enfermedad } \\
\text { definitoria de SIDA) }\end{array}$ \\
\hline $\begin{array}{l}\text { Exposición al virus } \\
\text { Epstein-Barr (VEB) }\end{array}$ & $90 \%$ & $15-30 \%$ & $40 \%$ \\
\hline Translocación t(8;14) & $\begin{array}{l}\text { En fase temprana } \\
\text { del desarrollo de linfocitos B }\end{array}$ & En fase tardía & \\
\hline
\end{tabular}

Tabla 1. Formas clínicas del linfoma de Burkitt. 
4. Montes Moreno S. Libro Blanco de la Anatomía Patológica en España. Ed Sociedad Española de Anatomía Patológica. International Academy of Pathology. Edición 2015. Pp 90-137

5. Gastwirt JP, Roschewski M. Management of adults with Burkitt lymphoma. Clin Adv Hematol Oncol. 2018; 16(12): 812-822.

6. Oosten LEM, Chamuleau MED, Thielen FW, de Wreede LC, Siemes C, Doorduijn JK, et al. Treatment of sporadic Burkitt lymphoma in adults, a retrospective comparison of four treatment regimens. Ann Hematol. 2018; 97(2): 255-266. doi: 10.1007/s00277-017-3167-7.
7. Wilson WH, Bromberg JE, Stetler-Stevenson M, Steinberg SM, Martin-Martin L, Muñiz C, et al. Detection and outcome of occult leptomeningeal disease in diffuse large B-cell lymphoma and Burkitt lymphoma. Haematologica. 2014; 99(7): 1228-35. doi: 10.3324/haematol.2013.101741.

8. O'Rourke E, Malone A, O'Marcaigh A, Storey L, Betts D, McDermott M, et al. Burkitt Lymphoma/Leukaemia in Children \& Young Adolescents. Ir Med J. 2020; 113(1): 6 